This paper is published in the open archive of Mid Sweden University

DIVA http://miun.diva-portal.org

with permission of the publisher

Citation for the peer-reviewed published paper:

Vesterlind E, Höglund H. Chemitermomechanical pulp made from birch at high temperature. ; Nordic Pulp \& Paper Research Journal. 2006;21(2):216-221.

URL to article at publishers site:

http://dx.doi.org/10.3183/NPPRJ-2006-21-02-p216-221 


\title{
Chemitermomechanical pulp made from birch at high temperature
}

\author{
Eva-Lotta Vesterlind and Hans Höglund, Mid Sweden University, Sundsvall, Sweden
}

KEYWORDS: CTMP, Birch, Pre-treatment. Pre-heating, Energy consumption, Paperboard, Bulk, Shive content

\begin{abstract}
SUMMARY: The inherent stiffness of birch wood-fibres makes birch an excellent raw material in the manufacture of high bulk pulp. By a combination of chemical impregnation of birch chips and pre-heating of the chips to high temperature prior to refining, it is possible to manufacture CTMP with very high bulk using a low energy input. Trials revealed that the high pre-heating temperature lowers the energy consumption considerably. At $500 \mathrm{ml} \mathrm{CSF}$ an increase in the pre-heating temperature from $110^{\circ} \mathrm{C}$ to $160^{\circ} \mathrm{C}$ reduced the energy consumption by more than $40 \%$. Despite the low energy input, the shive content remained low or was even reduced and the internal bond strength, in terms of Scott-Bond, compared favourably with Spruce CTMP. In summary, a high pre-heating temperature can be used to manufacture birch CTMP with very high bulk, at a low energy consumption.
\end{abstract}

\section{ADDRESS OF THE AUTHORS: Eva-Lotta Vesterlind (eva-lotta.vesterlind@miun.se) and Hans Höglund (hans.hoglund@miun.se): Mid Sweden University, Department of Natural Sciences, SE-851 70 Sundsvall, Sweden. \\ Corresponding author: Eva-Lotta Vesterlind}

Pressurised refining of chemically pre-treated wood chips, which have been pre-heated in water-saturated steam, is by no means a new technological process. However the potential of this technology has not been fully explored, in terms of processing conditions or in terms of raw material. We can, however, choose from a variety of species, and the significance of choosing the proper wood source for a certain end-product is often emphasised (Fredriksson and Höglund 1978; Fineman 1986; Höglund and Wilhelmsson 1993; Hatton 1997).

It may be due to well-known limitations, such as low yield or insufficient strength, that most hardwoods, except for low density hardwoods like poplars, have been somewhat neglected as the wood source for chemimechanical pulping, even though the present production of CTMP is more or less equally divided between the two types of wood (Canell and Cockram 2000). Like softwoods, hardwoods are not a homogeneous group. There is an enormous variation in terms of fibre morphology and wood polymer composition between softwoods (conifers) and hardwoods (deciduous) but even between different families of hardwood trees, due to factors such as growth location. Fig 1 shows how fibre dimensions may vary between species, even if the fibres differ quite a lot within trees of the same specie due, for instance, to differences in where they have grown. However, the purpose of the figure is to demonstrate typical fibre characteristics of a medium-density softwood (Scandinavian Spruce), a low-density hardwood like aspen
(Populus Tremula $\sim 460 \mathrm{~kg} / \mathrm{m} 3$ ) and a high-density hardwood such as birch (Betula Verrucosa $\sim 600 \mathrm{~kg} / \mathrm{m}^{3}$ ) (Rydholm 1965; Jackson 1988; Jackson et al. 1988; Udy 1994; Lindholm and Kurdin 1999).

The softwood earlywood has long, slender fibres with a large fibre width and a large lumen, while softwood latewood has a smaller fibre width and a significantly thicker fibre-wall. Long, slender fibres with low stiffness are ideal for obtaining good strength properties and a thin fibre-wall contributes to a large free surface area in the sheet structure, which gives the pulp good lightscattering properties. These characteristics make spruce an excellent raw material for high quality paper, such as printing and writing $(\mathrm{P} \& \mathrm{~W})$ grades. Hardwoods have shorter fibres with a small fibre width and lumen area, which of course has a great impact on pulp properties.

In Fig 1 the area moment of inertia, I, is given, which represents the estimated bending stiffness. The inertia, I, was calculated from a simplified but physically sound model in which the cross-sectional area is assumed to have a circular shape (Vesterlind and Höglund 2005). In the model the material properties, such as the E-modulus, are assumed to be the same regardless the type of wood. They are also assumed to be constant throughout the entire fibre-wall. If so, the bending stiffness will be governed by the moment of inertia. $I_{\max }$ is proportional to the bending stiffness at its maximum i.e. when the tubular fibre shape is intact. The combination of a large area at a large distance from the bending axis (in this case a large lumen) will be highly beneficial for bending stiffness. Spruce wood fibres combine both these factors. Spruce earlywood has a very large lumen area and its latewood has an exceptionally thick fibre-wall.

However, in the pulping process the fibres are made more or less flexible and this will affect their bending stiffness. The collapse resistance, $\mathrm{C}_{\mathrm{r}}$ (Vesterlind and Höglund 2005) is also shown in Fig 1. $\mathrm{C}_{\mathrm{r}}$ is proportional to the compression load needed to collapse the fibres. It increases with increased fibre-wall thickness and reduced fibre-width. This means that fibres such as birch fibres will be most resistant to collapse, whereas fibres from aspen and earlywood spruce collapse more easily. As the fibre is subjected to compression forces the bending stiffness will be affected and the impact of a partly distorted structure on stiffness is greater for fibres with a thin fibre-wall. This is illustrated by the term $\mathrm{I}_{\mathrm{sc}}$ (semicollapsed or partly collapsed fibres), which shows the range of inertia for fully and un-collapsed fibres in Fig 1 .

As implied by the name, hardwoods are considered denser (harder), even though deciduous wood intended for pulping is rarely of a very high density, and compared to softwood fibres, hardwood fibres are generally much shorter. Short fibres contribute to a uniform formation of 


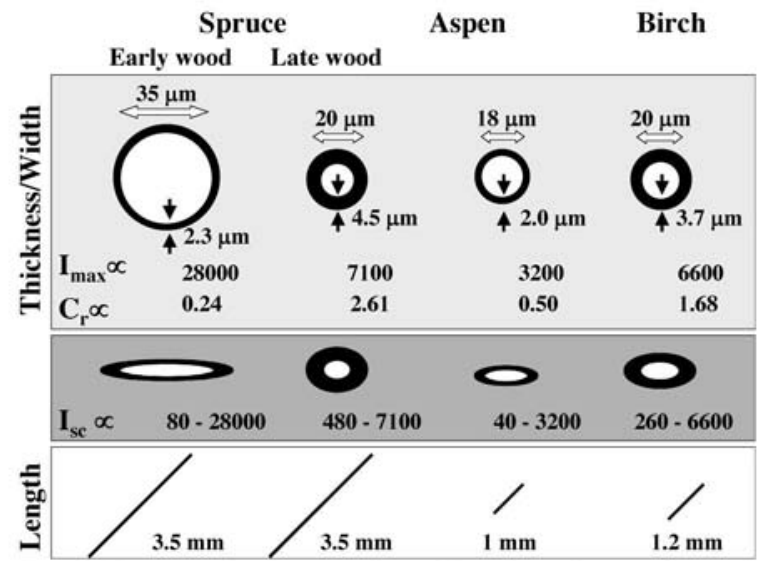

Fig 1. Schematic illustration of typical fibre dimensions and degree of possible fibre collapse of various types of wood.

the paper and improve surface smoothness. Aspen has a relatively thin fibre-wall compared to birch.

With this in mind, the production of $\mathrm{P} \& \mathrm{~W}$ paper should primarily use spruce with a high proportion of earlywood, or aspen, while the raw material and paper grades requiring high bulk should use spruce with a high proportion of latewood, or birch.

Not only are there morphological differences, but there are also major differences in the wood polymers between softwoods and hardwoods. For instance, the amount of cellulose is roughly the same in spruce (Picea Abies) and birch (Betula Pendula), but the amount of lignin is higher in spruce $(27 \%$ lignin in spruce compared to $21 \%$ in birch) and the hemi-celluloses are correspondingly lower. Due to the smaller amount of lignin, birch cannot be sulphonated to the same extent as spruce (Lindholm and Kurdin 1999). Moreover, the distribution of the wood components differs slightly between the two types of wood e.g. hardwoods are sometimes said to have a higher concentration of lignin in the middle lamella than softwoods (Rydholm 1965; Jackson 1988; Jackson et al. 1988). And, of course, all of this has implications for the processing of hardwood CTMP. Adapting the chemical charge according to the lignin structure and type of hemicelluloses is therefore of great importance. It is common knowledge that sulphonation reduces the shive content and has a bleaching effect on both hardwood and softwood CTMP. Alkali, on the other hand, increases the pulp strength of hardwoods, but has a negative effect on brightness and COD (Katz et al. 1981).

In conclusion, given the morphological and chemical properties of a high-density hardwood like birch, this type of wood would seem to be a primary choice for the production of high bulk pulp. The CTMP produced from high-density hardwood should give a pulp with high bulk, low shive content, sufficient internal bond-strength and high brightness, and be produced with a low energy input.

For the purpose of this paper, pilot trials were carried out at Metso Paper R\&D, Sundsvall and mill trials at the SCA Östrand mill, Timrå. The intention of the trials was to examine how the energy consumption and pulp properties of birch CTMP are influenced by the temperature in the pre-heater, the rotational speed of the refiner discs and also by the amount of chemicals used in the pre-treatment.

\section{Experiment}

\section{Pilot trials}

The pilot trials were carried out at Metso Paper, Sundsvall, Sweden, in an OVP-20" single disc refiner. The technical data are presented in Table 1. The rotational speed was varied between two levels, 1500 and 3000 rpm. It should be noted that the impregnation vessel is situated inside the pre-heater, which is not normally the case in a CTMP-plant. The residence time in the preheater was kept as short as possible, i.e. approximately 1 minute. The chips were atmospherically steamed before impregnation to assure a good chemical up-take. The chips were impregnated with $3 \%$ sodium sulphite, $\mathrm{Na}_{2} \mathrm{SO}_{3}$, and $2 \%$ sodium hydroxide, $\mathrm{NaOH}$, (based on dry wood).

\section{Mill trials}

Mill trials were performed at the SCA Östrand mill in Timrå, Sweden. The technical data from the mill plant are presented in Table 1. As in the case of the pilot plant, the impregnation vessel is situated inside the pre-heater. The chips were atmospherically steamed before impregnation. The residence time in the pre-heater was approximately 5-6 minutes. The chemical impregnation was $2 \% \mathrm{Na}_{2} \mathrm{SO}_{3}$ and $0.5-1.5 \% \mathrm{NaOH}$ (based on dry wood) and the rotational speed was $1500 \mathrm{rpm}$.

For more a detailed description of the layout of the pilot and mill plants, see (Vesterlind et al. 2005).

Table 1. Technical data of pilot and mill trials

\begin{tabular}{lll}
\hline Equipment & Pilot & Mill (main refiner) \\
\hline Type & SD. OVP & SD.RGP268 \\
Size & $20^{\prime \prime}$ & $68^{\prime \prime}$ \\
Speed & $1500-3000 \mathrm{rpm}$ & $1500 \mathrm{rpm}$ \\
Load & Max $300 \mathrm{~kW}$ & Max $15 \mathrm{MW}$ \\
Segments & 5811 & 268300 \\
Production rate & $1-2 \mathrm{~kg} / \mathrm{min}$ & $9-12 \mathrm{t} / \mathrm{h}$ \\
Pre-heating temp. & $110-175^{\circ} \mathrm{C}$ & $110-175^{\circ} \mathrm{C}$ \\
Pre-heating time & $1-7 \mathrm{~min}$ & $5-10 \mathrm{~min}$ \\
& & \\
\hline
\end{tabular}

\section{Pulp testing}

Pulp properties were tested in accordance with ISO or Tappi standards. The pulps were also evaluated for COD (SS-EN 028142 Dr Lange) and sulphur content (SCAN CM 38:96). Before the analysis of COD and sulphur was made, the pulp (15 g) was washed in milli-Q water (350 $\mathrm{ml})$ at $60^{\circ} \mathrm{C}$ for 10 minutes under vigorous stirring. The suspension was then filtrated through a Büchner funnel using vacuum suction and the filtrate was recirculated four times through the fibre pad, after which it was wetted with $100 \mathrm{ml}$ milli-Q water $\left(60^{\circ} \mathrm{C}\right)$. After a final suction, the filtrate was diluted to 1 litre and left to cool for 30 minutes before the COD-analysis was performed.

In order to demonstrate the effects of the conditions during sheet drying on the strength and bulk of birch CTMP, $65 \mathrm{~g} / \mathrm{m}^{2}$ laboratory sheets were also dried in a hotplate dryer (HP dryer) (Nygren et al. 2003). Two pressures $(100$ and $400 \mathrm{kPa})$ and two temperatures $\left(20^{\circ} \mathrm{C}\right.$ 
and $95^{\circ} \mathrm{C}$ ) were chosen for the drying of the sheets. In the HP-dryer, the pressure and temperature are maintained during sheet consolidation i.e. until the sheets are absolutely dry.

Pilot trials are quite sensitive to natural variations, such as the condition of the equipment and the quality of raw material, during the runs. It is therefore important for a correct evaluation of pilot trials intended for identification of general trends and effects that the conditions prevailing during the runs are as close to identical as possible. Therefore, it is crucial that trials aimed for comparison are performed on one occasion.

The sole purpose of this investigation was to identify large technical effects and general trends in pulp quality when refiner rotational speed and pre-heating temperature were changed. In order to be able to establish such trends and effects the pilot trials in this investigation were performed on two occasions. The first occasion aimed to establish the effect of an increased rotational speed and the other to establish the effect of pre-heating temperature. The intervals chosen for the investigations were significantly broadened to avoid uncertainties in the evaluation.

Birch chips (Betula Verrucosa/Pendula) were used throughout the investigation.

\section{Results and Discussion}

\section{Pilot plant}

To establish the effect of the refining intensity on birch CTMP, two rotational speeds and two pre-heating temperatures were used, Fig 2. An increased rotational speed resulted in a lowering of the energy consumption, the effect being larger with the lower pre-heating temperature. It is reasonable to assume that the energy reduction could be attributed to a shorter residence time and smaller gap in the refiner which increases the bar impulse moment, as seen in the mechanical pulping of spruce (Sundholm et al. 1987; Wikman et al. 2003).

The effect of the pre-heating temperature on energy consumption was also apparent. If the temperature was raised from $125^{\circ} \mathrm{C}$ to $160^{\circ} \mathrm{C}, \sim 30 \%$ less energy was needed to reach CSF $500 \mathrm{ml}$ (which is considered to be a bulky quality), when using $3000 \mathrm{rpm}$.

To investigate in more detail how the pre-heating

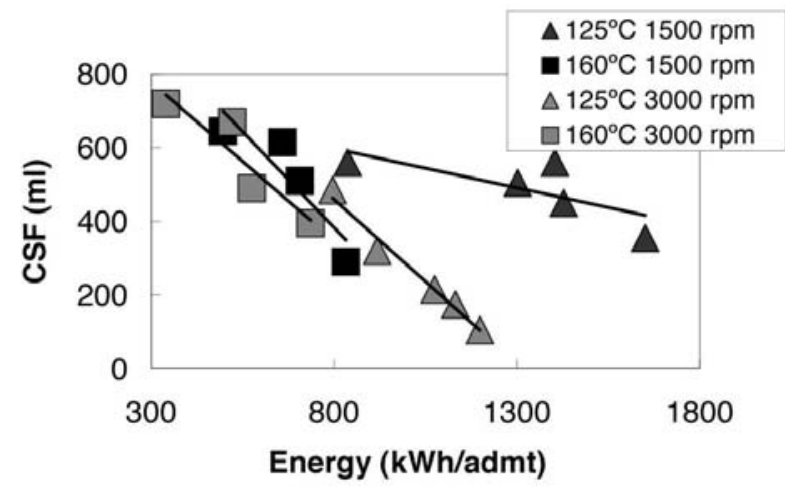

Fig 2. CSF vs. Energy consumption.

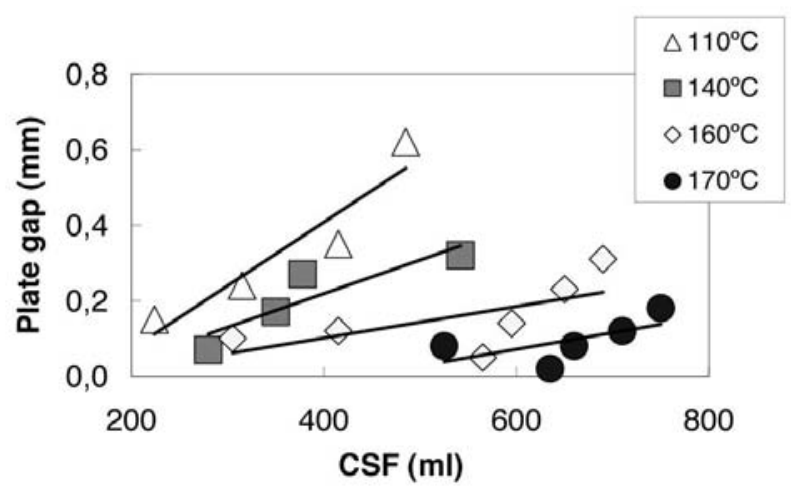

Fig 3. Plate gap vs. CSF.

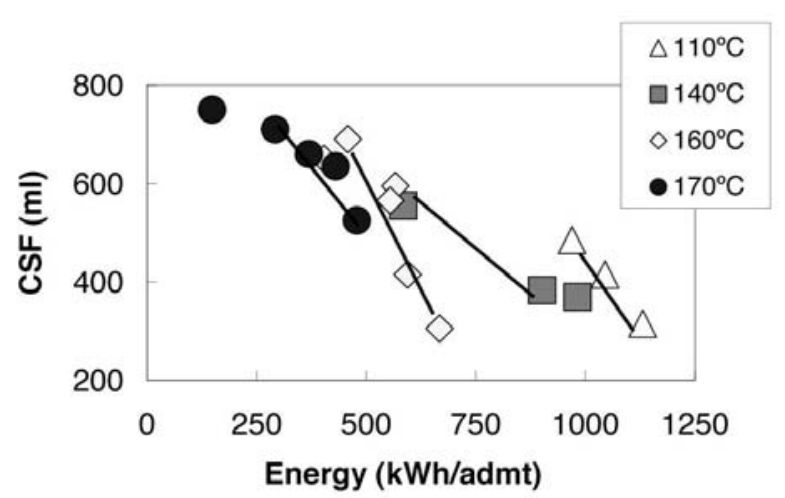

Fig 4. CSF vs. Energy consumption.

temperature affects the energy consumption and pulp properties, a temperature trial was made, with the rotational speed kept constant at $1500 \mathrm{rpm}$. It is well known from earlier studies that a high temperature in the pre-heater gives a significantly decreased plate gap and a diminished operating window, which was also the case here, see Fig 3. This is believed to be the result of the smaller volume of water-saturated steam and more compressible fibres. Not only does this affect runnability, but it also makes it difficult to produce a wide range of freeness levels in one-stage refining.

Even so, it was evident that the pre-heating of birch chips to sufficiently high temperatures rendered a reduction in energy consumption to reach a certain freeness, see Fig 4.

At approximately $500 \mathrm{ml}$ CFS the energy consumption was reduced by $\sim 40 \%$ when the temperature in the preheater was raised from $110^{\circ} \mathrm{C}$ to $160^{\circ} \mathrm{C}$. The energy reduction cannot be interpreted as solely an effect of increased thermal softening, but is probably an effect of the combination of more extensive thermal softening, faster sulphonation kinetics and decreased yield. An unintended effect of the higher temperature was an increase in COD - which corresponds to a decrease in yield, see Fig 5. However, the amount of COD is also closely connected to the amount of alkali used in the impregnation, and the residence time in the pre-heater. In Fig 5, a mill trial is included in the diagram, in which the amount of alkali charged in the impregnation was varied.

The most important factor for maintaining a given yield level is obviously a question of the interaction between the alkali charge and the pre-heating temperature. Utilising a high temperature in the pre-heater requires 


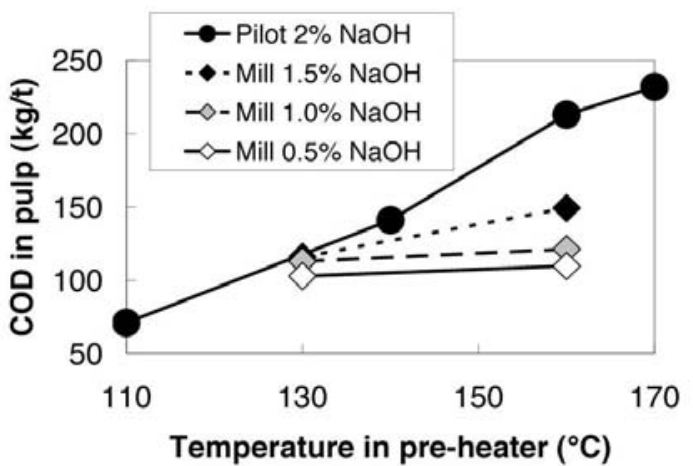

Fig 5. COD vs. Pre-heating temperature.

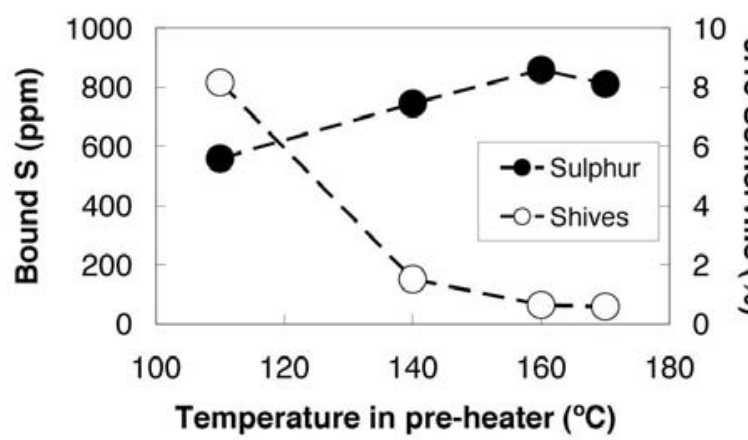

Fig 6. Bound S (left y-axis, upper curve) and Somerville shives (right y-axis, lower curve) vs. Pre-heating temperature. CSF $\sim 500 \mathrm{ml}$.

lower alkali charge to maintain the yield. Obviously, the residence time in the pre-heater is also an important factor. Unfortunately, the effects of a shorter residence time on the COD could not be evaluated in this pilot trial. When the pre-heating temperature was raised there was an increase in bound sulphur, as expected (Engstrand and Hammar 1991). The more extensive sulphonation added to the reduction of the shive content, see Fig 6. Nevertheless, the main cause for the reduction in the shive content seemed to be related to the elevated pre-heating temperatures or, more specifically, the gradually reduced plate gap with increased temperature. Raising the temperature from $110^{\circ} \mathrm{C}$ to $140^{\circ} \mathrm{C}$ reduced the shives from $8 \%$ to $1.5 \%$ at a freeness of $500 \mathrm{ml}$.

Pre-heating at elevated temperatures reduced the amount of shives significantly at all energy inputs, see Fig 7. At a pre-heating temperature of $170^{\circ} \mathrm{C}$ with very low energy consumption ( $300 \mathrm{kWh} / \mathrm{t}$, compare Fig 4), the shive content surprisingly was not increased. However, at such a high temperature the shive content can be successfully reduced by a very small increase in the energy input. The combination of a narrow plate gap due to the high temperature and more effective sulphonation makes it possible to produce high freeness pulp with a very low amount of shives.

An increased pre-heating temperature is often claimed to affect the light absorption coefficient negatively. In this trial, the negative effect of a raised pre-heating temperature on the light absorption coefficient was not evident, Fig 8 .

However, previous trials have shown that the light absorption coefficient can actually be lowered when a high pre-heating temperature is used. But, how the brightness is affected by the pre-treatment depends not

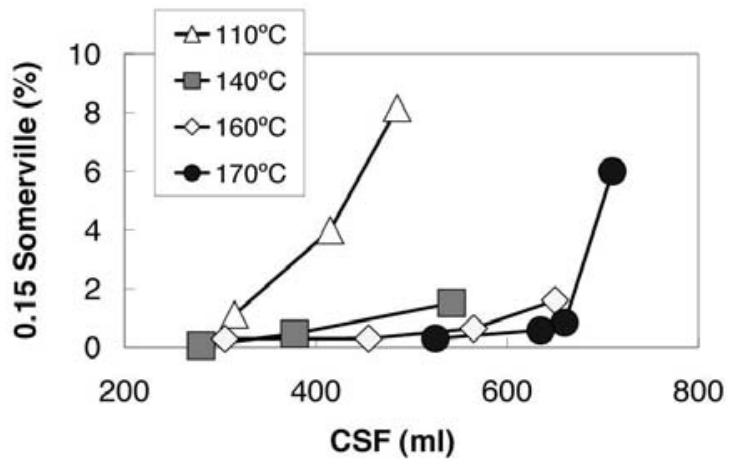

Fig. 7. Somerville shives vs. CSF.

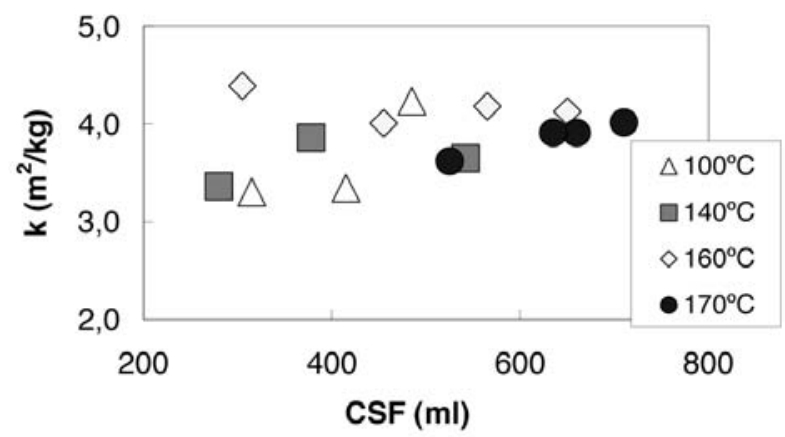

Fig. 8. Light absorption coefficient vs. CSF.

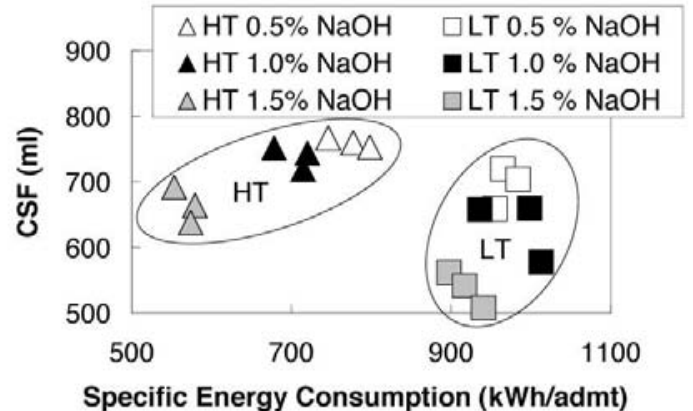

Fig 9. CSF vs. Energy (main refiner) - mill trial $\left(2 \% \mathrm{Na}_{2} \mathrm{SO}_{3}\right)$.

only on the temperature during pre-heating but even on the quality of the raw material, how well the chips are impregnated and on the residence time in the pre-heater. As the initial sulphonation is very rapid and as the reaction proceeds even faster when the temperature is raised (Engstrand and Hammar 1991; Vesterlind and Höglund 2005), there is no need for a prolonged preheating at a high temperature, which could be harmful to pulp brightness. Furthermore, this type of pulp has proved to be easily bleached to a high brightness level ( 85\%), (Vesterlind et al. 2005).

\section{Mill plant trials}

Pulp produced at a low pre-heating temperature will hereafter be denoted LT (Low Temperature $\sim 130^{\circ} \mathrm{C}$ ) CTMP and pulp produced at a high temperature, HT (High Temperature $\sim 160^{\circ} \mathrm{C}$ ) CTMP.

A high temperature technique (HT-technique) can be used even when the production rate is high. The preheating of birch chips to a high temperature makes it possible to liberate the fibres using a very low energy input compared to that used when pre-heating birch chips to a low temperature, see Fig 9. 
Increasing the alkali charge enhances the effect. At a high pre-heating temperature, alkali can be used to efficiently control energy consumption - a lowered alkali charge results in an increased freeness (and thereby also a higher bulk) with a very low shive content.

The evaluation of the pulp in Figs 10-13 is made on screened and flash dried pulp, most of which had been bleached. The conditions in the pre-treatment and bleaching can vary slightly.

At very high temperature ranges and with high sulphite charges it is generally acknowledged that the fracture zone in the wood structure is shifted into the middle lamella and that pulp strength may be reduced. This means that the pulp produced will have less of the strength-enhancing fines and well fibrillated fibre surfaces (Cisneros et al. 1995). This will result in reduced light-scattering and also lower strength. Nevertheless, a comparison of mill-produced spruce CTMP and birch CTMP (both HT and LT) reveals that birch HT CTMP appears on the same curve in a Scott-Bond/bulk plot as does spruce CTMP, see Fig 10. However, as will be discussed later, the evaluation of mill-produced pulps was made using ISO sheets, and the strength properties may therefore be somewhat underestimated.

Due to the very narrow plate gap that prevails at high temperatures, HT birch CTMP had less shives at a given bulk than did LT birch CTMP and spruce CTMP (despite the low energy input for HT birch), see Fig 11. However, more results have to be included in the figure before the extent of this effect can be established. Because of the very narrow plate gap that prevails at high temperatures there is also an obvious risk for fibre cutting, which eventually will affect strength and bulk negatively. However, the reduction of the long-fibre fraction with freeness as more energy was applied corresponded to the normal development of CTMP.

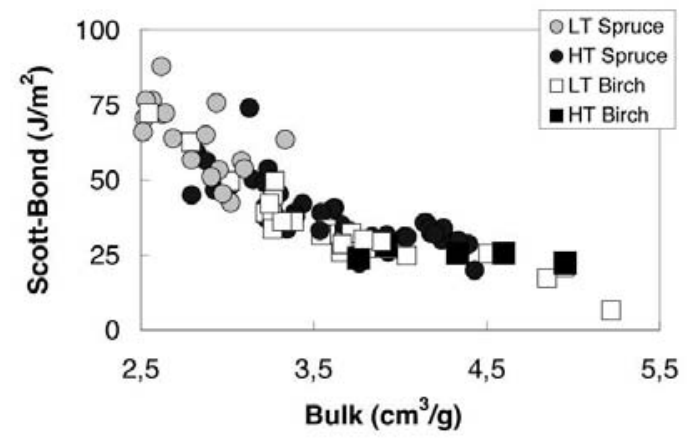

Fig 10. Scott-Bond vs. Bulk - mill trial.

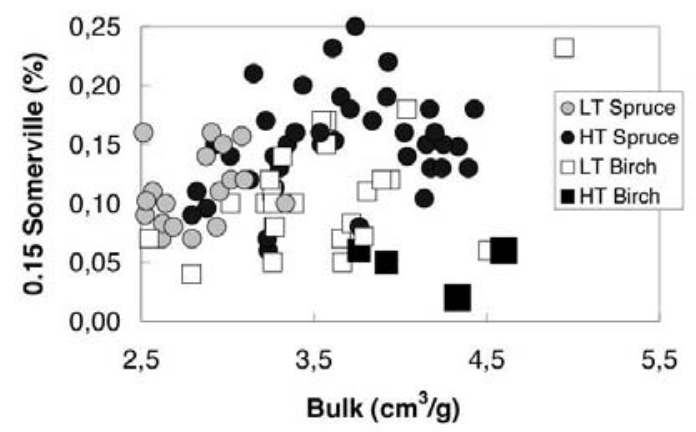

Fig 11. Shives vs. Bulk - mill trial.

\section{Effects of conditions during sheet consilidation on pulp properties}

As indicated earlier, the properties of the handsheets are not only a result of the pulp pre-treatment. The conditions during sheet consolidation have a large impact on the fibre-wall stiffness and consequently on the pulp properties. This is of special significance for high-yield pulps (Nygren et al. 2003). The strength properties of a highyield pulp such as HT birch CTMP are actually considerably better than the results shown in the testing of ISO or TAPPI handsheets.

Figs 12 and 13 show how the Scott-bond and bulk of two different mill-produced high-yield pulps and a hardwood kraft pulp were affected by different drying conditions. The extent of the strength development is the result of the fibre-wall stiffness and freeness at the temperature and pressure used during sheet consolidation. The thicker the fibre-wall and the higher the freeness of the pulp, the larger is the impact of the drying temperature on the strength. Even so, when birch CTMP of a lower freeness is compared to spruce CTMP of a higher freeness, it is seen that the effect of drying conditions on strength development is more pronounced for the birch CTMP. When the applied pressure was $400 \mathrm{kPa}$ and the temperature $95^{\circ} \mathrm{C}$ during sheet drying, birch CTMP approached the internal bond strength of the hardwood kraft pulp.

Therefore, the chosen method for sheet drying is of great importance when evaluating birch CTMP. Furthermore, given the morphological differences between different types of woods, the importance of choo-

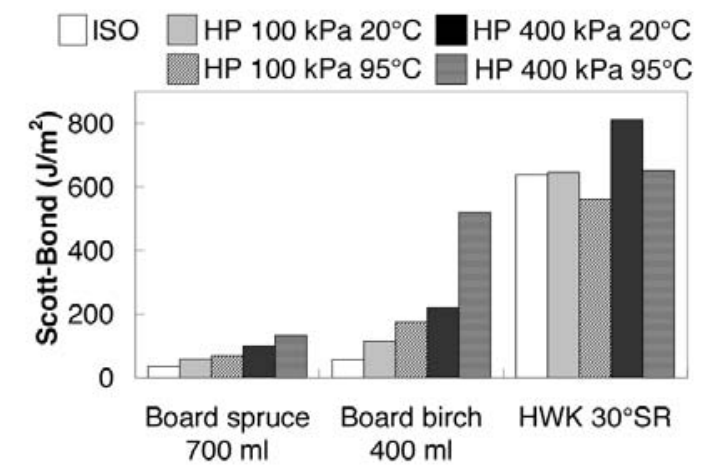

Fig 12. Development of Scott-Bond with raised drying temperature and pressure for spruce CTMP, birch CTMP and HWK (30SR).

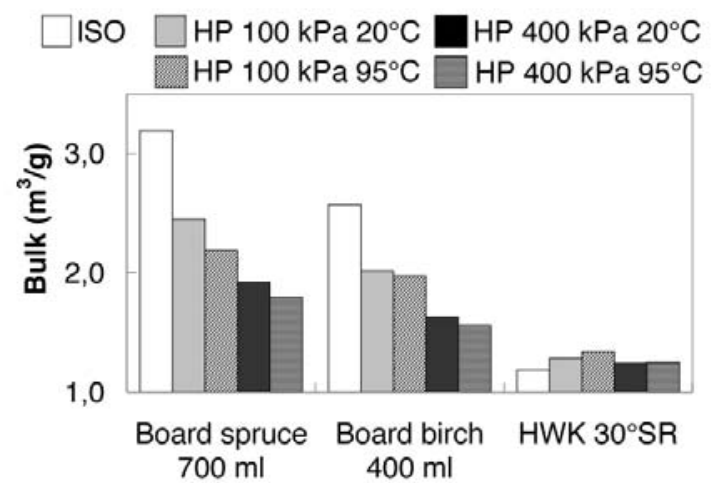

Fig 13. Development in bulk with raised drying temperature and pressure for spruce CTMP, birch CTMP and HWK (305R). 
sing the proper raw material becomes even more critical.

There are, however, ways to improve strength properties by chemical modification of the fibre surfaces. By covering the fibres alternately with positively charged and negatively charged polyelectrolytes the internal bond strength can be substantially increased without adversely affecting the bulk (Petterson et al. 2005).

\section{Conclusions}

The basic characteristics of birch make it an ideal raw material for paper products demanding high bulk. By utilising high temperature in the pre-heating of birch chips in a CTMP process these features are exploited, making it possible to produce high freeness pulp with a very low energy input. The pulp obtained is very low in shive content. The internal bond strength, in terms of Scott-Bond, at a given bulk compares well with spruce CTMP. Furthermore, the internal bond strength of birch CTMP is often underestimated due to irrelevant conditions during sheet consolidation. With a high preheating temperature the pulp suffers from a loss in yield (increased COD).

\section{Acknowledgements}

We would like to express our thanks to the staff at the Fiber Technology Center at Metso Paper in Sundsvall and SCA Östrand mill in Timrå, especially Mr Milan Kolar and Mr Jörgen Bergström, for assistance during the trials, to Mr Olof Nygren for his assistance with the HP-dryer trials and also to Professor Per Gradin for providing the physical models used in this study.

We gratefully acknowledge the Foundation for Knowledge and Competence, the Swedish Energy Agency and the European Union, Objective 1, Region of South Forest Counties for their financial support.

\section{Literature}

Canell, C. and R. Cockram (2000): The future of BCTMP, special editorial report, Pulp Paper, 74(5): 61-75.

Cisneros, H. A., G. J. Williams and J. V. Hatton (1995): Fibre surface characteristics of hardwood refiner pulps, J. Pulp Paper Sci. 21(5): 178-184.

Engstrand, P. and L.-Å. Hammar (1991): The kinetics of sulphonation and chro- mophore elimination in birch wood during sulphite treatment, Pulp and Paper Manufacture - European Seminar, Grenoble, France, 25-31.

Fineman, I. (1986): Let the product guide the choice of mechanical pulp, Nord. Pulp Pap. Res. J. 1(2): 10-14.

Fredriksson, B. and H. Höglund (1978): Chemithermomechanical pulps in different paper grades, Appita J. 31(5): 365-370.

Hatton, J. V. (1997): Pulping and papermaking properties of managed secondgrowth softwoods, Tappi J. 80(1): 178-184.

Höglund, H. and K. Wilhelmsson (1993): The product must determine the choice of wood type in mechanical pulping, International Mechanical Pulping Conference, Oslo, Norway, 1: 1-22.

Jackson, M. (1988): High yield pulps from canadian hardwoods, Nord. Pulp Pap. Res. J. Special Issue, Otto Brauns 85 years): 40-44.

Jackson, M., B. Falk, S. Moldenius and A. Edström (1988): The manufacture and end-use potential of high-yield pulp from eucalyptus, Pulp Paper Can. 89(10): 79-86

Katz, S., N. Liebergott and A. M. Scallan (1981): A Mechanism for the Alkali Strenghtening of Mechanical Pulps, Tappi, 64(7): 97-100.

Lindholm, C.-A. and J. A. Kurdin (1999): Mechanical Pulping, Mechanical Pulping, textbook, pp 76-77, p 227.

Nygren, 0., R. Bäck and H. Höglund (2003): On the characterization of mechanical pulps, International Mechanical Pulping Conference, Quebec, Canada, 97-104.

Petterson, G., L. Wågberg and H. Höglund (2005): Bulky papers with high internal bond strength, International Mechanical Pulping Conference, Oslo, Norway, 126-132.

Rydholm, S. A. (1965): Pulping processes, textbook, Chapter 2-3, pp 42-89. Sundholm, J., A. Heikkurinen and B. Mannström (1987): The role of rate of rotation and frequency in refiner mechanical pulping, International Mechanical Pulping Conference, Vancouver, Canada, 45-51.

Udy, D. J. (1994): Custom-tailoring high-yield pulp to meet end-product requirements, Pulp Paper, 71-74.

Vesterlind, E.-L. and H. Höglund (2005): Chemithermomechanical pulp made from birch at high temperature, SPCl International Conference, Stockholm, Sweden.

Vesterlind, E.-L., H. Höglund, M. Kolar and J. Bergström (2005): Low energy birch CTMP in bulky paper products, International Mechanical Pulping Conference, Oslo, Norway, 119-125.

Wikman, K., M. Leskelä, M. Pekkola, P. Vuorio, J. Tyrväinen and J.-P. Huhtanen (2003): New refiner segments technology to optimze the aspen BCTMP pulping process, International Mechanical Pulping Conference, Quebec, Canada, 91-95. 